\section{Unilateral mydriasis after induction of anaesthesia}

\author{
Richard C. Prielipp MD
}

tation pupillaire droite ( $7 \mathrm{~mm}$, ne réagissant pas à la lumière) après lintubation trachéale par bronchoscopie et linduction de l'anesthésie générale chez une femme de 74 ans de santé fragile présentant des subluxations cervicales avec atteinte médullaire. L'étiologie de la mydriase unilatérale comprend les effets des agents anesthésiques, le bloc du ganglion stellaire, une entrave au retour veineux de la tête et du cou, l'apparition d'une masse intracrânienne ou un accident hémorragique, un traumatisme oculaire, un condition médicale ou chirurgicale préexistante, ou linstillation accidentelle de substances alphaadrénergiques ou anticholinergiques. Après avoir révisé tous ces facteurs et considéré l'innervation autonome de l'oeil, un test d'éveil peropératoire a permis d'évaluer adéquatement l'état neurologique et de continuer la chirurgie. Une mydriase unilatérale quoique rare, peut survenir pendant l'anesthésie et son diagnostic nécessite une connaissance approfondie des voies autonomes et de la pharmacologie oculaires. Dans ce cas-ci, on considère que la mydriase est le résultat de la vaporisation de phényléphrine et de lidocaine utilisée pour produire l'anesthésie topique des voies aériennes.

Pupil size and reactivity, reflecting autonomic innervation of the pupil balancing sympathetic (dilator) and parasympathetic (constrictor) pathways, are fundamental to the neurological examination. Unilateral mydriasis is a disturbing and unusual finding during anaesthesia. I would like to report a case of an elderly woman who exhibited a dilated right pupil $(7 \mathrm{~mm})$ after the induction of general anaesthesia.

\section{Case report}

A frail, 74-yr-old, 49-kg woman presented with symptoms of severe localized neck discomfort, and a subaxial $\left(\mathrm{C}_{3}-\mathrm{C}_{7}\right)$, bilateral upper extremity radicular pain. She was scheduled for stabilization of multiple cervical subluxations and spondylosis at $\mathrm{C}_{3}-\mathrm{C}_{7}$, complicated by cord impingement. She had a medical history of childhood rheumatic fever, chronic hypertension, and debilitating rheumatoid arthritis requiring glucocorticoid therapy (prednisone $7.5 \mathrm{mg}$ twice daily). Six years before the current admission, progressive mitral stenosis precipitated atrial fibrillation and pulmonary oedema, necessitating emergency mitral commissurotomy. She currently expe- 
rienced no exertional dyspnoea or chest pain, but had persistent mild bilateral ankle swelling. Surgical history included a left renal artery transluminal angioplasty to control chronic hypertension. Current medications were digoxin $0.25 \mathrm{mg}$ daily, furosemide $40 \mathrm{mg}$ daily, prednisone $7.5 \mathrm{mg}$ daily, and potassium chloride $10 \mathrm{mEq}$ b.i.d.

Preoperative assessment demonstrated a thin woman with her head and neck supported by a hard neck collar in no distress with multiple cutaneous ecchymoses. The pupils were equal, reactive to light, and the optic fundi were within normal limits. Cardiac auscultation revealed an irregularly, irregular rhythm, mitral opening snap, a grade 3/6 pansystolic blowing murmur, and a grade $2 / 6$ mid-diastolic rumbling murmur at the apex. Chest $x$-ray showed cardiomegaly, left atrial enlargement, and mitral valve calcification. Her ECG revealed atrial fibrillation with a ventricular response rate of 90 , right axis deviation, and ST segment abnormalities consistent with digitalis administration. Doppler echocardiogram showed mild mitral stenosis (calculated valve area of $1.4 \mathrm{~cm}^{2}$, and a mean gradient of $9 \mathrm{mmHg}$ ), moderate mitral regurgitation with a thickened, immobile posterior leaflet, concentric left ventricular hypertrophy and normal systolic function, severe bilateral atrial enlargement, and mild right ventricular hypertrophy with pulmonary hypertension (estimated systolic pressure in the range of 45-50 $\mathrm{mmHg}$ ).

The patient was reassessed in the anaesthesia holding room, peripheral intravenous access secured, and topical anaesthesia of the entire airway (to allow selection of either an oral or nasal route of intubation) begun by the holding-room nurse with a standard oxygen-driven face mask nebulizer ("Up-Mist" by Hospitak (ii)) using a solution of $4 \%$ lidocaine and $0.5 \%$ phenylephrine (total dose $400 \mathrm{mg}$ lidocaine and $50 \mathrm{mg}$ phenylephrine). The patient was then transported to the operating room, where nasal oxygen $\left(4 \mathrm{~L} \cdot \mathrm{min}^{-1}\right)$ and routine monitors were applied, along with placement of a right radial arterial catheter. The patient was comfortable and relaxed after oral benzocaine spray (10\%) and intravenous sedation (midazolam $2 \mathrm{mg}$ and fentanyl $100 \mu \mathrm{g}$ ). While the head and neck were stabilized in a neutral position by her neck collar and in-line axial traction, a Pentax fibreoptic bronchoscope (FB-18RX) was advanced orally via a Patel airway. ${ }^{1}$ The vocal cords were easily visualized and sprayed with $3 \mathrm{~mL}, 1 \%$ lidocaine. A $6.5 \mathrm{~mm}$ tracheal tube was readily advanced intratracheally, and its position confirmed by auscultation of bilateral breath sounds and detection of end-tidal carbon dioxide. After tracheal intubation, the patient briefly became hypertensive (blood pressure $190 / 100 \mathrm{mmHg}$ ), which resolved after iv etomidate (14 mg), vecuronium $5 \mathrm{mg}$, and inhalation of $0.5 \%$ isoflurane. With the patient supine (no head-down tilt) and the neck maintained in a neutral midline position, a right internal jugular central venous catheter was inserted without difficulty. With a hard cervical collar supporting the head and neck, the patient was gently transferred to a Stryker surgical bed, Gardner-Wells tongs were placed, and ten pounds of skeletal traction were applied.

During surgical skin preparation and final positioning, Duratears 10 ointment was instilled bilaterally in the conjunctival sacs. Examination of the right eye revealed a markedly dilated right pupil $(7 \mathrm{~mm})$ which was nonreactive to direct and consensual light reflex. The left pupil was $3 \mathrm{~mm}$, and normally reactive to light. Neither eye was oedematous, injected, or showed signs of pressure or traumatic injury. Additional checks of the medical record confirmed no history of anisocoria, eye surgery, or a prosthetic eye. Vital signs remained stable. Neuromuscular blockade was reversed with neostigmine $(4 \mathrm{mg})$ and glycopyrrolate $(0.8 \mathrm{mg})$, and the lungs were ventilated with $100 \%$ oxygen. After four minutes, she became arousable, and readily followed commands, with strong motor movements in all four extremities. She was reanaesthetized with isoflurane and midazolam. Upon questioning the holding-room nurse, we confirmed that the adult-sized nebulizer face mask was a poor fit owing to the patient's petite stature. To avoid the nebulizer mist spraying out around the top of her mask, the patient selectively kept one eye (her dominant right) open. Thus, the right eye was exposed to a prolonged, dilute spray of the phenylephrine/lidocaine solution. With this information and a normal "wake-up test," we felt that surgery could proceed.

The patient underwent both an anterior discectomy and fusion, and a posterior cervical fusion and plating from $\mathrm{C}_{3}$ to $\mathrm{C}_{7}$. Blood loss was $300 \mathrm{~mL}$ during the fivehour operation. Repeat examination of her pupils remained unchanged. At the end of surgery, the patient's neuromuscular blockade was reversed, but because of shallow respiratory efforts, the trachea remained intubated and the lungs were ventilated while in the ICU. Over the next six hours, her right pupil constricted, and became reactive to direct and consensual light reflexes. Her vision was unchanged from her preoperative baseline. The trachea was extubated and she recovered uneventfully.

\section{Discussion}

Despite an apparently routine fibreoptic intubation, complicated only by brief systolic and diastolic hypertension, the unilateral mydriasis noted intraoperatively was alarming and at first, perplexing. Pupil size and reactivity are fundamental to the neurological examination, and a new, fixed, unilateral mydriasis may indicate severe neurolog- 
ical injury to the central nervous system. ${ }^{2}$ Systematic intraoperative review of these parameters and a "wake-up test" allowed us to make a diagnosis, and surgery to proceed.

Anisocoria may result from many causes during general anaesthesia, including effects of unusual anaesthetic agents such as the inhalation of diethyl ether. Specific possibilities in this patient included mechanical causes such as manipulation and dislocation of an unstable cervical spine resulting in Horner's syndrome, or asymmetric impaired venous return from the head and neck (i.e., malposition of the rigid neck collar), resulting in a unilateral dilated pupil and usually concurrent exophthalmos. Insertion of a central venous catheter may also produce a stellate ganglion block with Horner's syndrome due to either direct needling or after injection of local anaesthetic (but would most likely have resulted in a small right pupil following right internal jugular vein cannulation). However, difficult central venous access may produce an expanding deep neck haematoma, resulting in asymmetric impaired venous return and an ipsilateral dilated pupil. Hypertension after intubation focused concern on an acute intracranial mass lesion from a catastrophic intracranial haemorrhagic event (e.g., undiagnosed intracranial aneurysm). Lastly, direct eye trauma during intubation, pre-existing medical or surgical conditions (e.g., Adie's pupil), and inadvertent direct deposition of alpha-adrenergic or anticholinergic agents in or near the eye were considered. Careful neurological assessment afforded by an intraoperative wake-up test, along with retrospective analysis of the phenylephrine exposure (to only the dominant right eye) allowed surgery to proceed safely. In the absence of this explanation, we believe emergency computerized tomography of the brain would have been indicated.

Previous reports have documented unilateral mydriasis precipitated by unintentional alpha-adrenergic drug exposure. ${ }^{3-6}$ Both Rubin and Louis reported postoperative mydriasis after phenylephrine was used for mucosal vasoconstriction during nasal intubation., ${ }^{3,4}$ Gibson et al. reported postoperative mydriasis after nasal reconstruction surgery was carried out with cocaine-soaked pledgetts and epinephrine-containing local anaesthetic mucosal injections. ${ }^{5}$ Common to all these previous reports is the postoperative recognition of the mydriasis, and a similar mechanism of action with retrograde migration of phenylephrine (or similar mydriatic solutions) via the nasolacrimal duct into the conjunctival sac. ${ }^{5,6}$ The nasolacrimal duct is a conduit from the nose to the eye, especially when the patient is in a supine position and gravity assists retrograde flow. Our report is unique for two reasons: we observed the unilateral mydriasis intraoperatively, and we are the first to report these changes after topical, "spray" exposure from a nebulized solution of phenylephrine.

Normal autonomic innervation of the pupil is a balance of sympathetic (dilator) and parasympathetic (constrictor) pathways. The dilator pupillae muscle is arranged radially around the iris, and receives sympathetic fibres via the superior cervical ganglion which enter the eye via the long ciliary nerves of the first division of the trigeminal nerve. ${ }^{2}$ The sphincter pupillae muscle of the iris is innervated by parasympathetic fibres arising in the EdingerWestphal nucleus of the midbrain third cranial nerve complex, and enters the eye via the short ciliary nerves. ${ }^{2}$ Pupil dilation for diagnostic purpose is achieved by pharmacologic stimulation of the sympathetic system, e.g., ephedrine (3-5\%), hydroxyamphetamine (1-3\%), or phenylephrine (1-2\%), which usually lasts a few to several hours, without causing cycloplegia. ${ }^{7,8}$ Alternatively, blockade of the parasympathetic pathways (e.g., atropine, scopolamine) result in pupil dilation and cycloplegia. In addition, in a bright environment such as the operating room, a drug-induced mydriasis in the index eye is accompanied by a consensual miosis in the contralateral eye, probably owing to operation of the pupillary light reflex. ${ }^{7}$ Thymoxamine hydrochloride, an alphaadrenergic blocking agent, is one means to hasten the reversal of a phenylephrine-induced mydriasis. ${ }^{9,10}$

While approximately $10-20 \%$ of the general population has perceptible anisocoria $(\geq 1 \mathrm{~mm})$, a unilateral fixed, dilated pupil is seen in a relatively limited number of neurological disturbances. Ophthalmoplegia interna may occur in meningitis, vasculitis, and encephalitis, as well as with certain toxins such as diphtheria or botulism. Adie's tonic pupil, most frequently encountered in young women, may appear to be fixed and dilated, but upon close examination demonstrates a slow, tonic reaction to both light and accommodation. Traumatic contusion or rupture of the sphincter muscle may also result in an irregular fixed, dilated pupil. Finally, a unilateral fixed, dilated pupil may be indicative of coma (Hutchinson pupil) secondary to an intracranial mass lesion. An expanding intracranial, supratentorial lesion may cause downward displacement of the hippocampal gyrus and uncal herniation, with compression of the third nerve across the edge of the tentorium. Thus, acute changes in pupil size and reactivity are essential to monitoring of head injury, intracranial haemorrhage, epidural and subdural haematomas, and after craniotomy.

In conclusion, we encountered a new neurological deficit shortly after the induction of anaesthesia in a patient with an unstable cervical spine, hypertension, and cardiac disease. Unilateral mydriasis may reflect alterations in either sympathetic or parasympathetic autonomic tone, triggered by either a disturbance in cranial nerve function 
or a pharmacological alteration in autonomic nerve transmission. Systematic intraoperative review of these parameters and a "wake-up test" allowed us to make a diagnosis, and surgery to proceed. The assessment of perioperative unilateral mydriasis should include consideration of accidental exposure of mydriatic agents before or during surgery. Topical anaesthesia, like all forms of regional anaesthesia, may have potent actions at sites far removed from the one actually targeted. Awareness of these unexpected effects allows safe and efficient application of local anaesthetic techniques.

\section{References}

1 Patel VU, Stehling LC, Zauder HL. Fiberoptic Endoscopy in Anesthesia, Chicago: Year Book Medical Publishers, 1983; 75-113.

2 Bajandas FJ, Kline LB. Neuro-Ophthalmology Review Manual, 3rd ed., Thorofare, New Jersey: SLACK Inc., 1988; 113-24.

3 Rubin MM, Sadoff RS, Cozzi GM. Postoperative unilateral mydriasis due to phenylephrine: a case report. J Oral Maxillofac Surg 1990; 48: 621-3.

4 Louis F, Diab $M$. Prolonged unilateral mydriasis after nasotracheal intubation. Middle East J Anesthesiol 1988; 9: 471.

5 Gibson BE, Stanley RJ, Lanier WL. Prolonged unilateral mydriasis after nasal septal reconstruction (Letter). Anesth Analg 1987; 66: 197-8.

6 Stirt JA, Shuptrine JR, Sternick CS, Korbon GA. Anisocoria after anaesthesia. Can Anaesth Soc J 1985; 32: 422-4.

7 Theofilopoulos N, Longmore J, Kerr FA, Szabadi E, Bradshaw $C M$. Consensual pupillary responses to mydriatic and miotic drugs. Br J Clin Pharmacol 1988; 26: 697-702.

8 Alfonso E, Abelson MB, Smith LM. Pharmacologic pupillary modulation in the perioperative period. J Cataract Refract Surg 1988; 14: 78-80.

9 Wright MM, Skuta GL, Drake MV, et al. Time course of thymoxamine reversal of phenylephrine-induced mydriasis. Arch Ophthalmol 1990; 108: 1729-32.

10 Shah B, Hubbard B, Stewart-Jones JH, Edgar DF, Turner $P$. Influence of thymoxamine eye-drops on the mydriatic effect of tropicamide and phenylephrine alone and in combination. Ophthalmic Physiol Opt 1989; 9: 153-5. 